\title{
REMARKS ON VĂLEAN'S MASTER THEOREM OF SERIES
}

\author{
NECDET BATIR
}

Abstract. We generalize Vălean's Master Theorem of Series proved in [A master theorem of series and evaluation of a cubic harmonic series, J. Classical Analysis, 2(10), 2017, 97-107].

Mathematics subject classification (2010): Primary 40G10, Secondary 40A05. Keywords and phrases: Series, sums, harmonic numbers, Riemann zeta function.

\section{REFERENCES}

[1] C. I. VĂLEAN, A master theorem of series and evaluation of a cubic harmonic series, J. Classical Analysis 2 (10), 2017, 97-107. 